Commentary

Invited Commentary

Central Eur J Paed 2020;16(1):93-95

DOI $10.5457 / \mathrm{p} 2005-114.262$

\title{
The Challenge of Turning Peers into Active Defenders ${ }^{1}$
}

Sónia Seixas

Higher School of Education, Polytechnic Institute of Santarém, Santarém, Portugal

Correspondence: sonia.seixas@ese.ipsantarem.pt; Tel.: + 351243309 180; Fax.: + 351243309187

Received/Accepted: November 29, 2019

Key Words: Bullying - Bystander Roles - Empathy - Moral Disengagement.

School bullying is responsible for a serious number of biopsychosocial effects for students directly involved (1) and represents one of the highly important variables that influence mental health at school age. In addition, bullying is also a complex behaviour that occurs within a social context that goes beyond the interaction between the bully and the victim. As many other participants are involved, it becomes more clear that we should study bullying as a social phenomenon (2), by analysing the potential roles that peers play when facing bullying behaviour.

Salmivalli (3), addressing the different roles played by students not directly involved as bullies and victims, argues that bullying is maintained and encouraged by school members. The importance of investigations into these different participant roles is particularly important, knowing that peers are present in $85 \%$ of bullying episodes and only intervened in $11 \%$ (4).

To address this shortcoming, some studies focus on this aspect, particularly investigating or what other students do or how they behave when they observe aggression between the bully and the victim $(5,6,7,8)$. By studying bullies, victims and bystanders, these studies highlight the interdepen- dence nature of these roles. The "circle of bullying", proposed by Olweus (9), which includes five different participant roles besides the bully and the victim - followers and supporters of the bully, outsiders, possible defenders of the victim, and defenders, helps us to better understand peer relational dynamics. Considering these two different forms of involvement in defence of the victim, it seems that the group of students defenders deserves a closer look. We can identify the defenders who proactively defend the victim, the possible defenders who disapprove bullying but do not help or intervene (9), students who did nothing to help the victims, but felt guilty about it (10) and the aggressive defenders (11).

To better understand why defenders behave differently, it seems essential to analyse some of their individual characteristics. With this concern in mind, Raboteg-Saric and Bartakovic (11) in their study, lead us to discuss one of the most important issues in bullying prevention: What makes a peer to intervene?

In the past decade there has been a substantial increase in the number of studies conducted to evaluate the contribution of some individual characteristics in explaining bystander roles in bully-

${ }^{1}$ Invited Commentary on "Empathy and Moral Disengagement as Predictors of Bystander Roles in School Bullying” by RabotegSaric \& Bartakovic. 
ing and what determines students to intervene in defence of the victims. Among them, empathy has been the target of a large number of investigations. Several studies examine the role of empathy together with social cognitive factors (12), social self-efficacy (13), attachment (14), social preference and popularity (15). In general, high levels of empathy were positively associated with defender roles and negatively related to aggressive behaviours, both bullies and reinforcer role.

On the other hand, other investigations have focused on moral disengagement related to different bystander behaviour in bullying situations. While moral disengagement positively related to both forms of traditional peer aggression as well as cyber aggression (16), defenders show a lower level of moral disengagement $(17,18)$.

The review by Raboteg-Saric and Bartakovic (11), explore not only bystander roles in bullying, but also examine concurrently the effects of empathy and moral disengagement on bystanders' behaviour, understood as important determinants of their behaviour in bullying situations. An interesting result refers to the identification of a group of defenders, labelled aggressive defender, students who manifest more aggressive (verbal and physical) and revengeful behaviours towards the bullies, in the defence of the victims.

According to this study, although empathy is negatively related to aggressive behaviour it was also positively associated with the aggressive defenders, being the variable most strongly related to the defender role. On the contrary, moral disengagement had a positive association with aggressive behaviour being the strongest predictor of assistant and reinforcer roles.

More recently, studies on the participant roles in cyberbullying are standing out $(19,20)$. Being a current reality among our children and adolescents, it is also pertinent to understand which determinants influence their roles in cyberbullying and if there is a correlation with their participant roles in traditional bullying. At this level, we highlight the investigation of Knauf et al. (20) who found higher moral disengagement in cyberbullying as compared to school bullying students and the study of Schultze-Krumbholz et al. (21). In this study, the authors explored the roles in cyberbullying and also found prosocial defenders and aggressive defenders.

In sum, authors who understand bullying as a group phenomenon argue that peer behaviours greatly influence the persistence or decline of bullying behaviour, becoming not only a unit of analysis but also a prime intervention target (3). At this level, if the study of students' individual characteristics has important implications for the prevention of school bullying, the implementation of programmes that improve some students' socialcognitive skills is equally crucial. By improving self-awareness, self-management, social awareness, relationship skills and responsible decision-making competencies, Social and Emotional Learning (SEL) programmes have been understood as an effective component in bullying prevention programs $(22,23)$. Ultimately, a better understanding of which factors determine a proactive defending behaviour, like the identified characteristics in Raboteg-Šaric and Bartakovic study (11), can improve the chances of a better and more sustained intervention with bystander students and the development of more effective peer support training programs.

Conflict of Interest: The author declares that she has no conflict of interest.

\section{References}

1. Seixas S, Coelho JP, Nicolas-Fischer G. Bullies, victims and bully-victims: Impact on health profile. Educação Sociedade \& Culturas. 2013;38:51-73.

2. Swearer SM, Espelage, DL. A social-ecological framework of bullying among youth. In: Espelage, Swearer SM, editors. Bullying in North American schools. New York: NY: Routledge; 2011. p. 3-10.

3. Salmivalli, C. Participant role approach to school bullying: Implications for intervention. Journal of Adolescence. 1999;22 (4):453-9.

4. Craig W, Pepler D. Observations of bullying and victimization in the school yard. Canadian Journal of School Psychology. 1995;5(3-4):81-95. 
5. Craig W, Pepler D. Peer processes in bullying and victimization: an observational study. Exceptionality Education Canada. 19955 (3-4):81-95

6. Salmivalli C, Lagerspetz K, Bjorkqvist K, Osterman K, Kaukiainen A. Bullying as a group process: participant roles and their relations to social status within the group. Aggressive Behavior. 1996;22:1-15.

7. Tani F, Greenman P, Schneider B, Fregoso M. Bullying and the big five. A study of childhood personality and participant roles in bullying incidents. School Psychology International. 2003;24 (2);131-46.

8. Jeffrey L. Bullying bystanders. Prevention Researcher. 2004;1(3):7-8.

9. Olweus D. Bullying at school: What we know and what we can do. Oxford: Blackwell, 1993.

10. Obermann ML. Moral Disengagement Among Bystanders to School Bullying. Journal of School Violence. 2011;10(3)239-57.

11. Raboteg-Šaric Z, Bartakovic S. Empathy and Moral Disengagement as Predictors of Bystander Roles in School Bullying. Central European Journal of Paediatrics. 2019;15(2):161-76.

12. Barchia K, Bussey K. Predictors of student defenders of peer aggression victims: Empathy and social cognitive factors. International Journal of Behavioral Development. 2011;35(4):289-97.

13. Gini G, Albiero P, Benelli B, Altoe G. Determinants of adolescents' active defending and passive bystanding behavior in bullying. Journal of Adolescence. 2008;31(1):93105.

14. Nickerson AB, Mele D, Princiotta D. Attachment and empathy as predictors of roles as defenders or outsiders in bullying interactions. Journal of School Psychology. 2008;46(6):687-703.

15. Caravita SC, Di Blasio P, Salmivalli C. Unique and interactive effects of empathy and social status on involvement in bullying. Social Development. 2009;18(1):140-63.
16. Pornari CD, Wood J. Peer and cyber aggression in secondary school students: The role of moral disengagement, hostile attribution bias, and outcome expectancies. Aggressive Behavior. Official Journal of the International Society for Research on Aggression. 2010;36(2):81-94.

17. Obermann ML. Moral disengagement among bystanders to school bullying. Journal of School Violence. 2011;10(3):239-57.

18. Thornberg R, Jungert T. Bystander behavior in bullying situations: basic moral sensitivity, moral disengagement and defender self-efficacy. Journal of Adolescence. 2013;36(3):475-83.

19. Wachs S. Moral disengagement and emotional and social difficulties in bullying and cyberbullying: Differences by participant role. Emotional and Behavioural Difficulties. 2012;17(3-4):347-60.

20. Knauf RK, Eschenbeck H, Hock M. Bystanders of bullying: Social-cognitive and affective reactions to school bullying and cyberbullying. Cyberpsychology: Journal of Psychosocial Research on Cyberspace. 2018;12(4): [about 17 p.] Article 3. [cited 2019 Nov 19]. Available from: http:// dx.doi.org/10.5817/CP2018-4-3

21. Schultze-Krumbholz A, Hess M, Pfetsch J, Scheithauer H. Who is involved in cyberbullying? Latent class analysis of cyberbullying roles and their associations with aggression, self-esteem, and empathy. Cyberpsychology. Journal of Psychosocial Research on Cyberspace. 2018;12(4): [about 21 p.]. article 2, [cited 2019 Nov 19]. Available from: http://dx.doi.org/10.5817/CP2018-4-2

22. Espelage DL. Preventing youth violence and bullying through social-emotional school-based prevention programmes and frameworks. In: Donnolly PD, Ward CL, editors. Oxford textbook of violence prevention: Epidemiology, evidence, and policy. Oxford: Oxford University Press; 2015. p.155-60.

23. Smith BH, Low S. The role of social-emotional learning in bullying prevention efforts. Theory Into Practice. 2013;52(4):280-87. 